\title{
Agnès Hafez-Ergaut, Le Vertige du Vide - Huysmans, Céline, Sartre
}

\section{Emanuele Kanceff}

\section{(2) OpenEdition}

12 Journals

\section{Edizione digitale}

URL: http://journals.openedition.org/studifrancesi/9653

DOI: 10.4000/studifrancesi.9653

ISSN: 2421-5856

\section{Editore}

Rosenberg \& Sellier

\section{Edizione cartacea}

Data di pubblicazione: 1 décembre 2007

Paginazione: 693

ISSN: 0039-2944

\section{Notizia bibliografica digitale}

Emanuele Kanceff, «Agnès Hafez-Ergaut, Le Vertige du Vide - Huysmans, Céline, Sartre», Studi Francesi [Online], 153 (LI | III) | 2007, online dal 30 novembre 2015, consultato il 12 janvier 2021. URL: http:// journals.openedition.org/studifrancesi/9653 ; DOI: https://doi.org/10.4000/studifrancesi.9653

Questo documento è stato generato automaticamente il 12 janvier 2021.

\section{(c) $(1) \&$}

Studi Francesi è distribuita con Licenza Creative Commons Attribuzione - Non commerciale - Non opere derivate 4.0 Internazionale. 


\title{
Agnès Hafez-Ergaut, Le Vertige du Vide - Huysmans, Céline, Sartre
}

\author{
Emanuele Kanceff
}

\section{NOTIZIA}

AGNÈS HAFEZ-ERGAUT, Le Vertige du Vide - Huysmans, Céline, Sartre, Lewiston-QueenstonLampeter, The Edwin Mellen Press, c. 2000, pp. 319 (Coll. «Studies in French Literature», 42).

1 Si può immaginare l'imbarazzo dei catalogatori, gente pignola come è noto, di fronte a un libro che in copertina e sul dorso porta il titolo Le vertigue du vide... Tuttavia, certamente, la loro saggezza - e il dettato del frontespizio - li avranno facilmente convinti che quello che provano i tre scrittori citati è vertige. A prima vista, la filière Huysmans-Céline-Sartre non è evidente, nonostante la predilezione che quest'ultimo nutriva per il secondo. L'autrice, tuttavia, trova un filo conduttore molto solido nella nozione di brutto, di sordido, che percorre le tre opere e che si pone come elemento di peso nell'evoluzione letteraria dal Romanticismo al nichilismo novecentesco. Questa visione della letteratura "putrida", privata di ogni possibilità ideale, assume secondo l'Autrice una sua metafisica trascendenza, ovviamente negativa. Ella studia questo stato di precarietà maligna non solo nella sua evoluzione storica ma anche in tutti i suoi aspetti esteriori e interiori, per venire poi a esaminare le possibili vie d'uscita, dalla idealizzazione dell'arte al fascino esistenziale, dalla libertà esistenzialista all'engagement. È convinzione dell'Autrice che, nell'opera dei tre scrittori in oggetto, al di là delle particolarità individuali e delle esigenze della fiction, si assista alla stessa monografia narcisistica, allo stesso incantamento per il peso del tempo e la marcia della storia, alla stessa urgenza di fuggire il presente, sintomi che rivelano in loro l'angoscia di una società che muta. L'immagine sordida che ne deriva, portando a compimento il suo duplice obiettivo - che consiste nel singolarizzare l'entità individuale col ricorso al suo funzionamento fisiologico e, nello stesso tempo, a riassorbirla nel grande rimescolarsi della materia trionfante - si atteggia a metafora di questa tragedia 
dell'essere. Se l'individuo, schiavo dei propri fallimenti e sottomesso al duplice totalitarismo organico e sociale, si definisce con la fuga, se egli è essenzialmente materia, non può che riassorbirsi nella materia. Allora, l'uomo non può che dire con Céline: «Je veux m'écrouler, m'effondrer, me dissiper, me vaporiser, tendre nuage... en arabeques, dans le néant... dans les fontaines du mirage».

2 In sostanza, dunque, quale vertigine del vuoto provano i nostri autori? «Ainsi, ces trois auteurs - scrive l'autrice - quelle que soit leur orientation idéologique, imposent, dans leur désir de souveraineté, un double échec au projet démocratique égalitaire. En récusant l'atomisation individuelle par l'aspiration communautaire et le nivellement égalitaire par la revendication élitiste, ils expriment avec virulence ou désespoir, dans le délire ou par la réflexion rationnelle, leur renoncement à un système qui, dans le but d'accroître la puissance dévirilisante de l'Etat afin que celui-ci accomplisse sa visée séculaire, le contrôle total de la société, induit à l'explosion des rapports intersociaux et à l'atomisation des hommes». 